\title{
The incidence and magnitude of fibrinolytic activation in trauma patients: a rebuttal
}

\author{
C.R. RAMOS ${ }^{\star}$, E.E. MOORE ${ }^{\star}, \dagger$, M.L. MANCO-JOHNSON ${ }^{\ddagger}$, C.C. SILLIMAN ${ }^{\star}, \ddagger$, M.C. \\ CHAPMAN $^{*}$, and A. BANERJEE ${ }^{*}$ \\ *University of Colorado, Trauma Research Center, University of Colorado, Aurora, CO, USA \\ tDepartment of Surgery, Denver Health Medical Center, University of Colorado, Aurora, CO, USA \\ ¥Department of Pediatrics, Hematology, Oncology, BMT, University of Colorado, Aurora, CO, \\ USA
}

Trauma-induced coagulopathy (TIC) has been recognized as a potential preventable cause of mortality in $40 \%$ [1] of civilian deaths and $80 \%$ of military casualties [2]. Recent studies indicate that fibrinolysis may be a significant component of TIC in the most severely injured patients [3] and the CRASH2 study [4] has stimulated worldwide interest in this arena.

Although treatment is available to prevent plasmin-induced hyperfibrinolysis in the forms of aminocaproic acid and tranexamic acid, it is important to confirm the diagnosis of systematic hyperfibrinolysis before subjecting a patient to a potentially thrombogenic agent. Raza et al. [5] have questioned the validity of thrombelastometry (ROTEM) to identify pathologic fibrinolysis in injured patients, but we respectfully caution that their conclusions may be misleading owing to a number of reasons.

The gold standard, first developed in 1959, for evaluating fibrinolysis is the euglobulin lysis time (ELT) [6,7]. However, this time-consuming procedure is impractical for evaluation of the acutely injured patient. ROTEM and thrombelastography (TEG) have been used in elective cardiac surgical and liver transplant patients for decades for point-of-care detection of pathologic fibrinolysis [8,9]. Although present manufacturer recommendations for TEG and ROTEM assessment of fibrinolysis have been established in healthy individuals, these assays have not been validated in the trauma population. For example, Haemonetics has arbitrarily set their detection threshold for hyperfibrinolysis in their TEG instrument as a lysis of $<7.5 \%$ at $30 \mathrm{~min}$ (LY30) after achievement of the maximum amplitude [10]. But analysis of patients with severe trauma requiring a massive transfusion, at our urban Level I

(C) 2013 International Society on Thrombosis and Haemostasis

Correspondence: Christopher Ramos, Trauma Research Center, University of Colorado Denver, 12700 E. 19th Avenue, Room 6102, Mail Stop C320, Aurora, CO 80045, USA. Tel.: +1 (303) 724 6308; fax: +1 (303) 724 6310. christopher.ramos@ucdenver.edu.

Disclosure of Conflict of Interests

The authors state that they have no conflict of interest.

Addendum

C. R. Ramos: Primary Author, critical writing and revising, analysis and interpretation of data, final approval; E. E. Moore: Concept and design, analysis and interpretation of data, critical writing and revising, final approval; M. L. Manco-Johnson: Critical writing and revising, analysis and interpretation of data, final approval; C. C. Silliman: Critical writing and revising, final approval; M. C. Chapman: Critical writing and revising, final approval; A. Banerjee: Concept and design, analysis and interpretation of data, final approval. 
Trauma Center, revealed that $>3 \%$ lysis at $30 \mathrm{~min}$ by TEG was associated with an increase in mortality, 70 vs. $18.5 \%, P=0.002$, compared with lysis $<3 \%$ (Chapman MC, Moore EE, Ramos CR. Fibrinolysis above $3 \%$ is the critical value for initiation of anti-fibrinolytic therapy. J Trauma 2013 [In press]). Furthermore, we have documented a much lower TEG detection threshold for lysis with ELT (Ramos CR, Moore EE, Chapman MC. Defining post-injury hyperfibrinolysis with thrombelastography: technology in evolution. Shock Society 2013 [abst]). Presumably a similar issue exists for the ROTEM threshold for the detection of hyperfibrinolysis.

Raza et al.[5] defined severe fibrinolysis based upon a ROTEM maximal lysis of $>15 \%$ compared with the moderate group with a maximal lysis $<15 \%$. Both had plasminantiplasmin complex levels $>1500 \mu \mathrm{g} \mathrm{L}^{-1}$. The moderate and severe groups both had significant biomarkers of enzymatic fibrinolysis, including decreased antiplasmin and fibrinogen as well as increased D-dimer and TPA. A third group with elevated ROTEM lysis but normal levels of PAP complexes is noted to additionally differ from both the moderate and severe hyperfibrinolysis groups in having no changes in these biomarkers of hyperfibrinolysis. The TEM lysis only group did not differ from the normal group except in having lower D-dimer and prothrombin fragments $1+2$, which are opposite to the expected direction of change.

Furthermore, ROTEM has developed an assay in which aprotinin is added in vitro to the patient samples to inhibit the serine protease plasmin. This confirms plasmin-mediated clot dissociation by comparing the maximum lysis of a native sample (EXTEM) to the maximum lysis of a treated sample (APTEM). A potential explanation of the TEM lysis only group, using EXTEM, is (i) this small group ( $n=8)$ did not have hyperfibrinolysis and (ii) the maximal lysis $>15 \%$ produced on ROTEM is alternatively reflecting platelet retraction or a non-enzymatic change in fibroelastic character of the formed clot, as has been previously reported in healthy individuals $[11,12]$. Such alternative causes for the observed 'hyperfibrinolysis' is also consistent with the low mean injury severity score for this group [2-9]. We expect that in patients with normal biomarkers of fibrinolysis, as in this TEM lysis only group, the EXTEM and APTEM maximal lysis would not be different. Thus, it would be interesting to determine if there was a correlation between elevated PAP levels and the difference in maximal lysis between EXTEM and APTEM in all groups.

Finally, the massive elevations in PAP could be an artifact because the samples were not drawn into aprotinin and this has been previously described as a cause of falsely elevated PAP complexes [13-15]. Thus, an alternative explanation of the results of Raza et al. is (i) increased mortality occurs in patients with elevated fibrinolysis confirmed by plasma biomarkers and (ii) the group with negative biomarkers of proteolytic fibrinolysis are manifesting non-fibrinolytic changes in fibro-elastic clot characteristics.

In summary, we agree further studies are required to determine both TEG and ROTEM thresholds for pathologic fibrinolysis in the trauma population, and this should be systematically validated by ELT. 


\title{
Acknowledgments
}

\author{
Source of funding
}

This work was supported by the National Institutes of Health (P50 GM049222 T32 GM008315 grants).

\section{References}

1. Sauaia A, Moore FA, Moore EE, Moser KS, Brennan R, Read RA, Pons PT. Epidemiology of trauma deaths: a reassessment. J Trauma. 1995; 38:185-93. [PubMed: 7869433]

2. Pruitt BA Jr. Combat casualty care and surgical progress. Ann Surg. 2006; 243:715-29. [PubMed: 16772775]

3. Floccard B, Rugeri L, Faure A, Saint Denis M, Boyle EM, Peguet O, Levrat A, Guillame C, Marcotte G, Vulliez A, Hautin E, David JS, Negrier C, Allaouchiche B. Early coagulopathy in trauma patients: an on-scene and hospital admission study. Injury. 2012; 43:26-32. [PubMed: 21112053]

4. CRASH-2 Trial Collaborators 2010. Effects of tranexamic acid on death, vascular occlusive events, and blood transfusion in trauma patients with significant haemorrhage (CRASH-2): a randomised, placebo-controlled trial. Lancet. 2010; 376:23-32. [PubMed: 20554319]

5. Raza I, Davenport R, Rourke C, Platton S, Manson J, Spoors C, Khan S, De'ath HD, Allard S, Hart DP, Pasi KJ, Hunt BJ, Stanworth S, Maccallum PK, Brohi K. The incidence and magnitude of fibrinolytic activation in trauma patients. J Thromb Haemost. 2013; 11:307-14. [PubMed: 23176206]

6. Kowalski E, Kopeć M, Niewiarowski S. An evaluation of the euglobulin method for the determination of fibrinolysis. J Clin Pathol. 1959; 12:215-8. [PubMed: 13654539]

7. Smith AA, Jacobson LJ, Miller BI, Hathaway WE, Manco-Johnson MJ. A new euglobulin clot lysis assay for global fibrinolysis. Thromb Res. 2003; 112:329-37. [PubMed: 15041279]

8. Kang YG, Martin DJ, Marquez J, Lewis JH, Bontempo FA, Shaw BW Jr, Starzl TE, Winter PM. Intraoperative changes in blood coagulation and thrombelastographic monitoring in liver transplantation. Anesth Analg. 1985; 61:888-96. [PubMed: 3896028]

9. von Kaulla KN, Kaye H, von Kaulla E, Marchioro TL, Starzl TE. Changes in blood coagulation, before and after hepatectomv or transplantation in dogs and man. Arch Surg. 1966; 92:71-9. [PubMed: 5322193]

10. Haemonetics. TEG ${ }^{\circledR} 5000$ System User Manual. Vol. 28. Niles, IL: Haemonetics Corporation, Haemoscope Division; 2010. P/N 06-510-US, Manual revision: AC

11. Osdoit S, Rosa JP. Fibrin clot retraction by human platelets correlates with $\alpha_{\text {IIb }} \beta_{3}$ integrindependent protein tyrosine dephosphorylation. J Biol Chem. 2001; 276:6703-10. [PubMed: 11084040]

12. Katori N, Tanaka KA, Szlam F, Levy JH. The Effects of platelet count on clot retraction and tissue plasminogen activator-induced fibrinolysis on thrombelastography. Anesth Analg. 2005; 100:1781-5. [PubMed: 15920213]

13. Garabedian HD, Gold HK, Leinbach RC, Yasuda T, Johns JA, Thornton D, Collen D. Laboratory monitoring of hemostasis during thrombolytic therapy with recombinant human tissue-type plasminogen activator. Thromb Res. 1988; 50:121-33. [PubMed: 3135634]

14. Hoffmann JJ, Vijgen M. Prevention of in vitro fibrinogenolysis during laboratory monitoring of thrombolytic therapy with streptokinase or APSAC. Blood Coagul Fibrinolysis. 1991; 2:279-84. [PubMed: 1716481]

15. Hoffmann JJ, Kops O. Inhibition of desmoteplase-induced fibrinolytic activity in vitro. J Thromb Thrombolysis. 2005; 20:23-6. [PubMed: 16133891] 